\title{
OJS

\section{A IMPORTÂNCIA DO ESTÁGIO SUPERVISIONADO: A PERCEPÇÃO DISCENTE E DOCENTE SOBRE O CURSO DE LICENCIATURA PLENA EM GEOGRAFIA DA UNEMAT-MT}

\author{
Cristiane Gonçalves Ribeiro ${ }^{1}$, Renata Maria da Silva²
}

\begin{abstract}
1 Universidade do Estado de Mato Grosso (UNEMAT), E-mail: cristianegribeiro@outlook.com.br, Orcid: http://orcid.org/0000-0002-1557-9727

2 Universidade do Estado de Mato Grosso (UNEMAT), E-mail: renatamaria.enzo@gmail.com, Orcid: https://orcid.org/0000-0003-3919-962X
\end{abstract}

Artigo recebido em 24/08/2020 e aceito em 09/04/2021

\begin{abstract}
RESUMO
Este artigo tem como objetivo justificar a importância do estágio para o curso de licenciatura em Geografia, da Universidade do Estado de Mato Grosso, em razão de promover maior integração entre a aprendizagem acadêmica e a compreensão da dinâmica das instituições de educação básica, pois, assim, o aluno pode estabelecer relações entre a teoria estudada em sala de aula e a prática de ensino nas escolas. Para este estudo foram utilizadas a pesquisa bibliográfica, a documental e a participante. Destaca-se que a sistematização de observações e os dados coletados evidenciam a importância da preparação, da qualificação e da formação continuada dos estudantes. Desse modo, um estágio eficaz proporciona ao futuro professor condições satisfatórias de enfrentar e superar os desafios da profissão, pois, na prática, a docência assim exige. Por fim, é relevante frisar que o estágio é uma etapa imprescindível para o desenvolvimento profissional e, quando bem planejado e bem executado, certamente, propiciará sucesso na prática docente.
\end{abstract}

Palavras-chave: Estágio supervisionado; Licenciatura em geografia; Ciência geográfica.

\section{THE IMPORTANCE OF SUPERVISED PRACTICE: A LEARNING AND TEACHING VIEW ON THE LICENTIATE FULL DEGREE COURSE OF GEOGRAPHY OF UNEMAT-MT}

\begin{abstract}
This paper aims at justifying the importance of internship in the licentiate degree course of Geography, from the Mato Grosso State University, in the sense that it promotes a better integration between the academic learning and the comprehension of the dynamics of the institutions of basic education, so that students can establish relations between the theory studied in class and the teaching practice. To create this study, a bibliographic, documentary and participative research were conducted. It must be noted that the
\end{abstract}


systematization of observations and the data collected evince the importance of preparation, qualification and continuing education of students. Thus, an effective internship propitiates to the future teacher satisfactory conditions of facing and overcoming challenges of the profession, for, in practice, this is what the teaching profession demands. Finally, it is worth noting, too, that internship is an indispensable stage to the professional development and, when properly planned and executed, it will, certainly, propitiate success in the classroom practice.

Keywords: Supervised practice. Licentiate degree in Geography.Geographic science.

\title{
LA IMPORTANCIA DE LAS PRÁCTICAS SUPERVISADAS: LA PERCEPCIÓN DEL DISCENTE Y LA ENSEÑANZA SOBRE EL CURSO DE LICENCIA COMPLETA DE GEOGRAFÍA DE LA UNEMAT-MT
}

\begin{abstract}
RESUMEN
Este artículo tiene como objetivo justificar la importancia de la pasantía para la carrera de pregrado en Geografia, de la Universidad Estatal de Mato Grosso, porque promueve una mayor integración entre el aprendizaje académico y la comprensión de la dinámica de las instituciones de educación básica, porque, así, el alumno puede establecer relaciones entre la teoría estudiada en el aula y la práctica docente. Para este estudio se utilizó investigación bibliográfica, documental y participante. Es de destacar que la sistematización de las observaciones y los datos recolectados muestran la importancia de la preparación, calificación y educación continua de los estudiantes. Así, una pasantía efectiva brinda al futuro docente condiciones satisfactorias para afrontar y superar los retos de la profesión, porque, en la práctica, la docencia así lo requiere. Finalmente, es relevante enfatizar que la pasantía es un paso fundamental para el desarrollo profesional y, cuando está bien planificada y bien ejecutada, seguramente brindará éxito en la práctica docente.
\end{abstract}

Palabras clave: Prácticas supervisadas. Licenciatura em geografía. Ciencia geográfica.

\section{INTRODUÇÃO}

A Ciência Geográfica tem por objetivo o estudo e a compreensão do espaço geográfico, envolvendo os aspectos dialéticos e fenomenológicos, também faz o estudo das relações entre o homem e o meio ambiente. Sendo assim, a Ciência Geográfica estuda a superfície terrestre, bem como as relações mútuas dos fenômenos físicos, biológicos e sociais que nela se manifestam. Desse modo, sustentando constante diálogo com os debates atuais, essa ciência realiza análises críticas geográficas em escala global, nacional, regional e local. Além disso, também aborda as esferas econômica, social, cultural, política, física e ecológica.

Partindo do pressuposto de que o estágio supervisionado pode ser considerado uma disciplina acadêmica, quando realizado no ensino fundamental o trabalho docente dá ênfase à alfabetização, em sentido estrito, à aquisição da leitura e da escrita. Neste procedimento, tem-se também o ensino da 
Geografia, o qual acaba quase sempre relegado a segundo plano, ou seja, nada ou pouco é trabalhado sobre essa área do conhecimento nos anos iniciais do ensino fundamental, resultando na não aprendizagem de conceitos importantes, constitutivos da própria vida (CALLAI, 2010).

Nesse sentido, corroborando com esta análise, Straforini (2002, p. 96) afirma que:

\begin{abstract}
Sabemos que nos primeiros ciclos do Ensino Fundamental as aulas de Geografia, assim como das outras disciplinas que não sejam Português e Matemática, ocupam um papel secundário, muitas vezes irrelevante no cotidiano da escola. Sabemos que isso decorre da falta de discussões teóricas, metodológicas e epistemológicas, bem como do grande problema na formação dos professores das séries iniciais, que assumem as suas dificuldades perante a discussão teórica das referidas disciplinas.
\end{abstract}

Desta forma, no ensino médio, o conhecimento do professor deve estar muito bem fundamentado. "Para além de conhecer e conseguir interpretar a realidade do mundo, o geógrafo (a) precisa estar habilitado (a) a entender os mecanismos que levam o espaço a ser de um outro modo" (CALLAI, 2013, p. 123). E, também, tudo o que foi e será ensinado não terá valor sozinho. A verdadeira aprendizagem se dá com a nossa participação e com a nossa abertura por outra Geografia, por outra Globalização (SANTOS, 2008).

Assim, acerca da dimensão pedagógica do profissional de Geografia, Callai (2013, p. 111) sustenta que: "as Licenciaturas em geral têm trabalhado essa dimensão técnica na perspectiva das didáticas e práticas de ensino. Entendo que essa discussão tem de ser colocada noutros termos"; e na sequência: "a dimensão técnica é a que habilita o sujeito a desempenhar certa atividade profissional e a dimensão pedagógica é a que dá sentido ao trabalho. É a função social”.

Portanto, entender o modo como a Geografia compreende o mundo também contribui para sua construção, tornando-o sustentável e racional. Referente a isso, por meio dessa ciência pode-se fazer uma leitura coerente da relação entre espaço e técnica e, a partir dessa abordagem, determinar o equilíbrio da conexão entre técnica e natureza e, instrumentalizando o homem a poder refletir e decidir sobre as ações que irá empreender nesse contexto.

Nesse contexto, o professor tem um papel extremamente importante, pois cabe a ele, por meio do ensino de Geografia, propiciar o conhecimento e facilitar o entendimento da realidade em que o aluno vive, facilitando o acesso ao saber já produzido e à compreensão do processo social cotidianamente vivido. Ainda, para Pontuschka et al. (2001), mesmo diante dos obstáculos existentes no processo de ensino-aprendizagem da Geografia, ocorre a transformação do espaço.

Dessa maneira, a formação do professor de Geografia, deve ocorrer de forma contínua. Após o licenciado concluir a graduação, é importante que tenha construído o entendimento de forma está 
que entendemos ser inacabada sempre em busca de novos conhecimentos. Destaca-se, assim, que isso não quer dizer que o profissional teve uma formação precária. Conforme Callai (2013, p. 115):

\begin{abstract}
A formação do professor de Geografia deve estar referida a dois momentos: 1) a habilidade formal; 2) a formação num processo. A primeira é restrita à duração do curso de licenciatura e apresenta as características que vão depender da instituição em que é realizada. A segunda é permanente, decorre do "pensar e teorizar a própria prática" e se insere na integração do terceiro com o primeiro e segundo grau (atualmente universidade e ensino básico).
\end{abstract}

Nesse viés, o efetivo estágio deve proporcionar ao futuro professor a capacidade de enfrentar e superar os desafios da profissão, bem como desempenhar com eficiência à docência. Cabe frisar que o estágio é uma etapa imprescindível para o desenvolvimento profissional e, quando bem planejado e bem executado, propiciará o sucesso em sala de aula. Porém, o estágio é apenas o ponto de partida, a busca pela qualidade e pela eficiência deve ser uma constante na formação e no cotidiano do futuro professor. Neste sentido, Callai (2013, p. 105) declara que:

O geógrafo como profissional tem que dar conta de interpretar a realidade, fazendo análise do espaço enquanto um resultado do trabalho do homem para perceber que os problemas do território são mais que simples problemas do espaço, são questões sociais (dos homens) que precisam ser compreendidas.

Ainda, o Estágio Curricular Supervisionado, indispensável na formação de docentes nos cursos de licenciatura, é um processo de aprendizagem necessário a um profissional que deseja realmente estar preparado para enfrentar os desafios na docência, considerando a multiplicidade de questões que envolvem essa atuação.

Acrescenta-se que, como preparação à realização da prática em sala de aula, o tradicional estágio pode ser configurado como uma possibilidade de fazer a correlação entre teoria e prática e de conhecer a realidade da profissão que optou para desempenhar. Desse modo, quando o acadêmico tem contato com as atividades oportunizadas pelo estágio, ele inaugura reflexões e assimilações quanto ao quadro teórico estudado com o cotidiano do seu trabalho.

Diante disso, em razão das condições da educação brasileira, o objetivo deste artigo é justificar a importância do estágio para o curso de licenciatura em Geografia, da Universidade do Estado de Mato Grosso (UNEMAT-MT), em razão de promover maior integração entre a aprendizagem acadêmica e a compreensão da dinâmica das instituições de ensino, pois, assim, o aluno pode estabelecer relações entre a teoria estudada em sala de aula e a prática de ensino.

Para o desenvolvimento deste estudo, foram utilizadas as modalidades de pesquisa bibliográfica, documental e participante. Destaca-se que a sistematização das observações e os dados 
coletados evidenciam a importância da preparação, da qualificação e da formação continuada dos estudantes, pois dessa forma, além do preparo para a prática docente, há a possibilidade de alfabetização geográfica aos alunos dos anos iniciais do ensino fundamental ao ensino médio.

No cotidiano da docência, é importante que o professor de Geografia busque o diálogo com outros professores, na intenção de contribuir para a formação didático-pedagógica de todos, formando e sendo formado em um processo interdisciplinar, que pode estar representado em desenvolvimento de estudo e produção.

\begin{abstract}
Nesse sentido o próprio curso de graduação deve permitir aos licenciados que exercitem uma prática de sala de aula que não seja a mera repetição de conteúdos transmitidos a cada semestre, mas com uma linha metodológica que articule o ensino e a pesquisa. O professor da universidade deveria dar condições para que o próprio aluno consiga transformar as informações, as leituras, as discussões e exposições em sala de aula em um conhecimento organizado por ele próprio, isto é, que ele faça a construção de sua aprendizagem, exatamente aquilo que será exigido dele em sala de aula dos Ensinos Fundamental e Médio (CALLAI, 2003, p. 121).
\end{abstract}

A pesquisa participante caracteriza-se pelo envolvimento e identificação do pesquisador com as pessoas investigadas (FONSECA, 2002). Nesse sentido, para ser professor e pesquisador é necessário ter humildade, bem como trabalhar em prol das descobertas, objetivando que as pesquisas e estudos possam ser revertidos ao benefício dos estudantes. No caso específico deste estudo, almeja se que os resultados possam fortalecer a organização dos professores, inteirando a necessidade do contato inicial que se dá através do estágio.

Nesse contexto, ao analisar o conceito de participação, segundo Haguete (1987, p.142): “a ideia de participação envolve a presença ativa dos pesquisadores e de certa população em um projeto comum de investigação que é, ao mesmo tempo, um processo educativo, produzido dentro da ação".

Assim, o trabalho objetiva propiciar aos futuros licenciados em Geografia o entendimento de seus problemas para que eles possam percebê-los e levantar alternativas que vão ao encontro aos seus interesses. Ainda, justificar a importância do estágio curricular supervisionado para o curso de licenciatura em Geografia, da Universidade do Estado de Mato Grosso, pois, desse modo, caminhase em direção ao envolvimento dos estudantes como sujeitos do conhecimento.

Nessa perspectiva, o trabalho foi guiado por metodologias qualitativas de investigação, tais como observação participante, diálogos em sala (caderno de campo), visitas nas escolas, sempre fazendo as observações e anotações dos futuros profissionais licenciados. É no sentido desse esforço da busca da investigação e do conhecimento, que se apresenta este artigo. Desse modo, trata-se de uma reflexão que se desdobra em três partes. 
$\mathrm{Na}$ primeira parte o texto foi fundamentado em alguns autores para colocar em discussão determinados aspectos teórico-metodológicos sobre o curso de licenciatura em Geografia, da UNEMAT-MT, sobre o estágio supervisionado como disciplina na práxis.

Na sequência, aborda-se a prática do estágio supervisionado nas escolas, a importância do conceito de participação na prática do estágio, enquanto instigador de uma nova perspectiva nos trabalhos desenvolvidos na universidade e nas escolas, e com isso tem-se a segunda parte deste estudo. Na terceira etapa, busca-se ressaltar a percepção dos discentes com a prática do estágio, assim, é dedicado um espaço para o relato da experiência das pesquisadoras, que abarca o trabalho individual dos estudantes do oitavo semestre de Geografia.

\section{RESULTADOS E DISCUSSÃO}

\section{A UNIVERSIDADE DO ESTADO DE MATO GROSSO EM CÁCERES E O CURSO DE LICENCIATURA EM GEOGRAFIA ${ }^{1}$}

Com a fundação da Universidade Estadual de Mato Grosso na cidade de Cáceres em 10 de julho de 1978, sob o decreto municipal $\mathrm{n}^{\circ}$ 190, foi definida que a universidade seria estabelecida como Instituto Superior de Cáceres (IESC), e seria vinculada a Secretaria Municipal de Educação e Assistência Municipal. Suas atividades se deram início em 15 de agosto de 1978, ainda como autarquia Municipal.

No dia 30 de maio de 1984, por meio do Decreto Federal $\mathrm{n}^{\circ} 89.719$, foi autorizado o funcionamento dos cursos ministrados pelo Instituto. Na década de 1990, inicia-se a expansão da Instituição para outras regiões de Mato Grosso - o primeiro pólo a ser criado foi o de Sinop, em seguida, os de Alta Floresta, Alto Araguaia, Nova Xavantina, Pontes e Lacerda, Luciara, Barra do Bugres, Colíder, Tangará da Serra e Juara (todos na década de 1990, entretanto, Juara entrou em efetivo exercício em 2001).

Assim, por meio da Lei Complementar no 30, em 15 de novembro de 1993, instituiu-se a Universidade do Estado de Mato Grosso. Nesse ínterim, foi mantida pela Fundação Universidade do Estado de Mato Grosso (FUNEMAT), transformando em campus os antigos núcleos pedagógicos. Seu Estatuto foi homologado e aprovado pelo Conselho Estadual de Educação, em 10 de janeiro de

\footnotetext{
${ }^{1}$ As informações contidas neste tópico foram retiradas da página eletrônica da UNEMAT.
} 
1995, e em 10 de agosto de 1999, a universidade foi credenciada pelo Conselho Estadual de Educação por um prazo de cinco anos, passando a usufruir de autonomia didática, pedagógica e científica.

Atualmente, a UNEMAT conta com 13 campus (Diamantino e Nova Mutum sendo incluídos em 2013) com 17 núcleos pedagógicos e 24 pólos educacionais de Ensino a Distância. A instituição oferta 129 cursos em modalidade diferenciada e 60 cursos presenciais, dentre eles, na área de Ciências Humanas, está o curso de Licenciatura Plena em Geografia.

O curso de Geografia da UNEMAT foi criado no dia 30 de maio de 1984, por meio do Decreto Federal $\mathrm{n}^{\mathrm{o}}$ 89.719, o qual autorizou o funcionamento do curso de licenciatura curta em Estudos Sociais. Desse modo, com a extinção do referido curso, no primeiro semestre de 1990, foi implantado o curso de Licenciatura Plena em Geografia.

Frisa-se que o objetivo do curso de Licenciatura em Geografia, oferecido pela UNEMAT, corresponde à formação do profissional por meio da aquisição de conhecimentos, habilidades e atitudes para agir de forma criativa e eficiente na área do Ensino, em nível Fundamental, Médio e Superior, e nas áreas de pesquisa e de extensão, garantindo o desenvolvimento das capacidades de observação, interpretação e análise, para pensar criticamente a realidade, melhor compreendê-la e identificar as possibilidades de transformação no sentido de superar suas contradições.

Portanto, o licenciado em Geografia da Universidade do Estado de Mato Grosso dispõe de uma sólida formação no âmbito da ciência geográfica, com conhecimento e prática referente às atividades de docência, destacando-se também:

1- Atuação ética, crítica, autônoma e criativa; autonomia intelectual; respeito à pluralidade inerente aos ambientes profissionais e à própria sociedade como um todo; atuação propositiva na busca de soluções de questões colocadas pela sociedade;

2- Compreensão dos elementos e processos concernentes ao meio natural e ao construído com base nos fundamentos filosóficos, teóricos e metodológicos da Geografia e à aplicação desse conhecimento na busca do desenvolvimento social;

3- Domínio e permanente aprimoramento das abordagens científicas pertinentes ao processo de produção e aplicação do conhecimento geográfico.

No início de suas atividades de ensino, o curso foi autorizado a ofertar 30 vagas em período noturno e em regime semestral. Atualmente, são ofertadas 40 vagas semestrais, mantido o período noturno, com aulas e trabalhos de campo aos sábados. O curso tem duração de 8 (oito) semestres, no mínimo, e 14 (catorze) semestres no máximo. As aulas de estágio têm início no $6^{\circ}$ semestre, com 60 
horas; no $7^{\circ}$ semestre, cumpre 180 horas; e no $8^{\circ}$ e último semestre, cumpre mais 180 horas, finalizando e totalizando 400 horas de estágio supervisionado, contudo, essas horas-aulas compreendem aulas em sala de aula e aulas-campo - Prática de Ensino.

\section{O ESTÁGIO SUPERVISIONADO}

Atualmente, há três principais modalidades diferentes de estágio: as Monitorias, modalidade que consiste na inclusão de universitários dos cursos de graduação em atividades desempenhadas pelos alunos da própria universidade, em que são evidenciadas suas capacidades técnicas e didáticas em áreas particulares do conhecimento. A segunda modalidade é o Estágio Curricular não Obrigatório, o qual condiz com as atividades complementares ligadas à área de formação do aluno, de grande valia ao desenvolvimento profissional dos acadêmicos. A terceira modalidade é o Estágio Curricular Obrigatório, atividade assegurada na matriz curricular do curso, pode ser executada em instituições não governamentais (em programas de extensão) e em organizações privadas ou públicas (SCALABRIN; MOLINARI, 2013).

Conforme aponta Rodrigues (2013), em busca de melhorias no campo da educação, que há muito é desvalorizado, algumas medidas foram desenvolvidas, sendo possível citar como principais a Lei do Piso Nacional do Professor (lei no 11.738 de 16 de julho de 2008) e a Lei do Estágio (lei $n^{\circ}$. 11.788, de 25 de dezembro de 2008), as quais dispõem sobre o estágio de estudante. Acrescenta-se que o parecer $n^{\circ}$ 28/2001 estabelece a duração e carga horária dos cursos de formação de professores da Educação Básica em nível superior. Este parecer define também o estágio como um componente curricular obrigatório integrado à proposta pedagógica do curso de licenciatura, devendo ser executado sob a supervisão de um profissional habilitado.

Na Lei de Diretrizes e Bases (LDB), Lei no 9.394, de 20 de dezembro de 1996, em seu artigo 65, fica estabelecido que toda formação docente, com exceção ao Ensino Superior, deverá incluir a Prática de Ensino de 300 horas, no mínimo. Contudo, esse total de horas foi considerado insuficiente à formação profissional, deste modo, foi elaborado um novo parecer - Parecer $n^{\circ}$ 28/2001 em que determina o acréscimo de 100 horas de Estágio Supervisionado, totalizando 400 horas de Estágio Supervisionado aos cursos de licenciatura (RODRIGUES, 2013).

Neste sentido Scalabrin; Molinari, (2013), destaca que o estágio é uma prática de aprendizado por meio do exercício da profissão que será exercida no futuro, adicionando conhecimentos práticos aos teóricos aprendidos no curso. O estágio curricular obrigatório é uma atividade assegurada na 
matriz curricular do curso, cuja prática varia de acordo com este e pode ser realizada em organizações públicas, privadas, organizações não governamentais ou através de programas permanentes de extensão da universidade.

De acordo com Tardif (2002), o estágio curricular supervisionado constitui uma das etapas mais importantes na vida acadêmica dos alunos de licenciatura e, cumprindo as exigências da Lei de Diretrizes e Bases da Educação Nacional (LDBEN), a partir do ano de 2006, constitui-se em uma proposta de estágio curricular supervisionado com o objetivo de oportunizar ao estudante a observação, a pesquisa, o planejamento, a execução e a avaliação de atividades pedagógicas, permitindo a colocação da práxis em sala de aula.

Sobre o estágio curricular obrigatório, este se refere às atividades ligadas à área de formação do estudante, importantes para o desenvolvimento profissional, pois propicia maior tempo de intercâmbio entre a universidade e os espaços de atuação, melhorando, dessa forma, o método de aprendizagem, podendo ser desenvolvido em organizações instituições que mantêm parcerias com a universidade.

Destarte, o estágio curricular é compreendido:

\begin{abstract}
Como um processo de experiência prática, que aproxima o acadêmico da realidade de sua área de formação e o ajuda a compreender diversas teorias que conduzem ao exercício de sua profissão. É um elemento curricular essencial para o desenvolvimento dos alunos de graduação, sendo, também, um lugar de aproximação entre a universidade e a sociedade, permitindo uma integração à realidade social e assim igualmente no processo de desenvolvimento do meio como um todo, além de ter a possibilidade de verificar, na prática, toda a teoria adquirida nos bancos escolares. (SCALABRIN; MOLINARI, 2013, p. 11).
\end{abstract}

Dessa forma, corroborando com Fávero, (1992) o autor menciona que os estágios são importantes e permitem a aprendizagem como processo pedagógico de construção de conhecimentos, desenvolvimento de competências e habilidades por meio da supervisão de professores atuantes, sendo a relação direta práxis, unir teoria e prática é um grande desafio com o qual o futuro e atuais professores de um curso de licenciatura deve lidar.

Portanto, se esse problema não for resolvido, ou pelo menos suavizado, durante a vida acadêmica do estudante, essa dificuldade se refletirá em seu trabalho como futuro professor.

Ainda nesse contexto, as autoras Scalabrin e Molinari (2013) acrescentam que o "estágio supervisionado proporciona ao licenciado o domínio de instrumentos teóricos e práticos imprescindíveis à execução de suas funções”. Assim, busca-se, por meio desse exercício, beneficiar a experiência e promover o desenvolvimento no campo profissional, não adquiridos durante o curso, nas instituições superiores de ensino, bem como favorecer, por meio de diversos espaços educativos, 
a ampliação cultural dos acadêmicos e futuros professores. Além disso, outros fins previstos nesta proposta são: desenvolver habilidades, usos e maneiras relacionados à docência e criar condições para que os estagiários atuem com segurança e visão crítica em seu espaço de trabalho.

Pimenta e Lima (2008) reforçam que o aprendizado de qualquer profissão é prático. Ainda, que esse conhecimento ocorra a partir de observação e reprodução, em que o futuro educador repetirá aquilo que ele avalia como bom. Em outros termos, é um procedimento de escolhas, de adaptação, de adicionar ou retirar, sempre dependendo do contexto em que se encontra.

Ressalta-se que a grande relevância da disciplina de Geografia é desenvolver "a função técnica e social" (CALLAI, 2013, p. 112). Assim, situar a escola no contexto histórico ajudará os estudantes a entender o presente da escola, dessa forma, para ser protagonista de um futuro melhor, tanto para ele como para a escola, projetando nela a formação recebida em outras condições de educação.

\begin{abstract}
A tarefa do profissional desempenhando a função técnica e a função social do seu trabalho é conseguir dar conta de ser um cidadão que exerça de fato a sua cidadania, que realize a sua dimensão de intelectual orgânico, proposta por Gramsci em seus escritos. A relação entre teoria e prática, entre a produção do conhecimento e a sua colocação a serviço da população, seja através do ensino ou de tarefas profissionais, é contraditória, mas necessária, e é a forma de dar o significado social ao aprendizado que foi possível desenvolver com o acesso à universidade (CALLAI, 2013, p. 112).
\end{abstract}

Em sua acepção mais ampla, de acordo com Fernandes e Nascimento (2012), o estágio sugere dar condições ao aluno para a reflexão sobre seu fazer pedagógico mais abrangente, e assim construir a sua identidade profissional. Dessa maneira, o estágio é um campo de conhecimento, é uma aproximação do estagiário com a profissão que irá exercer e com os as pessoas com quem irá trabal har suas práticas, proporcionando a eles menos dificuldades futuras.

Além disso, conforme Scalabrin e Molinari (2013, p.06)

O aprendizado é muito mais eficiente quando é obtido por meio da experiência, na prática, o conhecimento é assimilado com muito mais eficácia, pois torna muito mais comum ao estagiário lembrar-se de atividades durante o percurso do seu estágio do que das atividades que realizou em sala de aula enquanto aluno.

Entendemos que a educação é responsável pela transformação e desenvolvimento social, por essa razão, a necessidade e importância do futuro professor ter consciência de estar assumindo algo que vai exigir dele uma entrega completa. (STRECK, 2018).

Conforme Freire (1999, p. 55), “ensinar não é transferir conhecimento, mas criar as possibilidades para a sua produção ou para a sua construção. Quem ensina aprende ao ensinar e quem aprende ensina ao aprender". Para isso, é imprescindível o desenvolvimento do estágio com 
consciência, porque somente assim o futuro professor terá a clareza do que ele enfrentará no cotidiano, sendo o melhor e fazendo o melhor.

\section{A PRÁTICA DO ESTÁGIO SUPERVISIONADO NAS ESCOLAS NA PERCEPÇÃO DOS DISCENTES}

Para esta pesquisa, contou-se com artigos elaborados pelos estudantes do oitavo semestre, tendo em vista que o artigo foi um dos critérios de avaliação da disciplina de estágio supervisonado. Assim, foram recebidos artigos dos 21 discentes matriculados na disciplina de estágio supervisionado IV da licenciatura em Geografia. Destes discentes, 10 são do sexo masculino e 11 do sexo feminino, e todos realizaram a prática do estágio supervisionado III no ensino fundamental e no ensino médio.

Destaca-se que esta pesquisa abarcou os discentes da última turma, os quais finalizaram o estágio supervisinado, na prática, com o Ensino Médio. Sendo assim, dentre esses estudantes, foram selecionados 8 (oito) artigos. É importante frisar que a escolha por estes trabalhos se deu em razão do grau de relevância apresentado tanto nas respostas como no objetivo da pesquisa. Para preservar a identidade dos alunos, utilizaram-se apenas as iniciais dos nomes. É importante mencionar que todos os estudantes analisados eram da Universidade do Estado de Mato Grosso (UNEMAT), campus Jani Vanini, em Cáceres.

A seguir, apresentação do planejamento das aulas da Disciplina: 98153 - ESTÁGIO SUPERVISIONADO NO ENSINO DE GEOGRAFIA IV. Turma: 2016/1 - CAC 98/3 Período: 2019/2. Disciplina oferecida: 229428.

Informa-se que as aulas iniciaram no dia 08 de agosto de 2019 e finalizaram no dia 19 de dezembro de 2019. Os estudantes tiveram 8 horas-aulas teóricas, em sala de aula, no oitavo semestre de Geografia, no campus Jani Vanini, ocorrendo nas quintas e sextas-feiras consecutivas. Posteriormente, as aulas práticas de estágio em que cada acadêmico realizou em uma escola pública, destacando que tais instituições receberam as pesquisadoras e concordaram com as práticas junto aos seus discentes. Nesta etapa, foi realizada a prática somente com alunos do Ensino Médio. 
Tabela 1 - Estágio supervisionado no ensino de geografia IV

\begin{tabular}{|c|c|}
\hline Objetivos & $\begin{array}{l}\text { Refletir sobre as bases teórico-metodológicas da Geografia e sua } \\
\text { constituição enquanto disciplina escolar. Possibilitar aos professores em } \\
\text { formaça,o, acadêmicos do } 8^{\circ} \text { semestre, o desenvolvimento de um conjunto } \\
\text { de atividades para pensar criticamente o espaço escolar e o modo de fazer } \\
\text { [ensino-aprendizagem] particular da ciência geográfica no ensino médio. }\end{array}$ \\
\hline Conteúdos & $\begin{array}{l}\text { *[1] Apresentação da disciplina e leitura da resolução 029/2012 CONEPE. } \\
\text { *Documentação de estágio. } \\
\text { *Reflexões sobre o texto Estágio e docência: diferentes concepções. } \\
\text { *Avaliação escolar como agente de exclusão social. } \\
\text { *Raciocínio geográfico e a teoria do reconhecimento na formação do } \\
\text { professor de geografia. } \\
\text { *Projeto político-pedagógico da escola: uma construção coletiva. } \\
\text { *A importância do planejamento de ensino para o bom desempenho do } \\
\text { professor em sala de aula. } \\
\text { *Causas da falência da educação pública. } \\
\text { *A entrega do ofício de apresentação do estagiário e a organização da } \\
\text { documentação do estágio. } \\
\text { *Contato do estagiário com a escola-campo. } \\
\text { *Estágio supervisionado no ensino da geografia. } \\
\text { *Organização do artigo. } \\
\text { *Contato do estagiário com a escola-campo. } \\
\text { * Organização e entrega da documentação do estágio. } \\
\text { *Organização e entrega da documentação do estágio e artigo. }\end{array}$ \\
\hline Metodologia & $\begin{array}{l}\text { A prática de ensino no estágio supervisionado em Geografia IV deve ser } \\
\text { compreendida como um momento significativo no processo de formação } \\
\text { docente do futuro professor de geografia, sendo realizada nas seguintes } \\
\text { fases distintas e complementares: } \\
\text { Reflexão em sala: leituras de textos previamente selecionados sobre } \\
\text { formação de professores, metodologias, propostas curriculares em } \\
\text { vigência, ensino médio, formação do educador e conhecimento dos } \\
\text { instrumentos empregados no estágio (proeg). } \\
\text { Grupos de estudos: consistirá em rodas de diálogos, em que cada grupo } \\
\text { terá a incumbência de conduzir as reflexões sobre os textos. Nessa etapa, } \\
\text { todos os grupos deverão ler os textos, para propiciar discussões e reflexões } \\
\text { sobre o material. } \\
\text { Período de observação e regência: os acadêmicos, munidos de } \\
\text { conhecimentos prévios e com o auxílio de um roteiro de observação, } \\
\text { deverão realizar uma pesquisa na escola-campo de estágio, } \\
\text { especificamente em seu PPP, com o intuito de conhecer a realidade na qual } \\
\text { irá atuar durante a regência. Cada aluno ou equipe, após uma observação } \\
\text { geral, centrará sua atenção em pontos específicos que tenham ligação com } \\
\text { seus interesses de estudo na licenciatura, especificamente no ensino de } \\
\text { geografia. A regência será destinada a aulas práticas, orientada e } \\
\text { supervisionada pelo professor responsável pela disciplina de estágio. }\end{array}$ \\
\hline
\end{tabular}




\begin{tabular}{|l|l|}
\hline & $\begin{array}{l}\text { Oficinas: em grupos, os acadêmicos irão desenvolver oficinas com o } \\
\text { objetivo de aprimorar a prática docente, com atividades variadas. } \\
\text { Caderno de estágio: a escrita, como ferramenta de trabalho que } \\
\text { acompanhará os alunos em todos os momentos da disciplina, nesta etapa } \\
\text { será fundamental e poderá ser feita através da escrita diário. Ao final do } \\
\text { período de observação e regência, o aluno deverá saber o tema e os } \\
\text { conteúdos do seu estágio, para que no seu retorno à universidade, possa dar } \\
\text { prosseguimento na construção de seu artigo de estágio. } \\
\text { Artigo: com auxílio dos materiais trabalhados na disciplina, com pesquisas } \\
\text { e outras fontes, cada acadêmico desenvolverá um artigo como resultado } \\
\text { das reflexões em sala de aula e das experiências vivenciadas no estágio. Os } \\
\text { resultados dos artigos serão expostos em um seminário final da disciplina. }\end{array}$ \\
\hline Avaliação & $\begin{array}{l}\text { Os conteúdos dessa disciplina serão abordados e discutidos, envolvendo } \\
\text { uma ação integradora de análise, diálogo e prática. A participação e o } \\
\text { diálogo entre os sujeitos envolvidos no processo são fundamentais para que } \\
\text { sejam elementos centrais da formação docente e profissional. Assim, a } \\
\text { avaliação dar-se-á de forma contínua e emancipatória. }\end{array}$ \\
\hline
\end{tabular}

Fonte: Elaborado pelas autoras (2020)

Ainda sobre a relevância do estágio supervisionado exigido nos cursos de licenciatura, destaca-se seu caráter indispensável, tendo em vista que se trata de um espaço de compreensão em que futuros professores e alunos devem seguir a mesma linha de pensamento, fazendo uso da mesma linguagem. Além disso, é essencial utilizar como ponto de partida o meio em que o aluno está inserido, pois isso possibilita constituir uma analogia, uma vez que é conhecendo sua realidade, e a partir dela, que se aprofundam conhecimentos.

Refletindo sobre a questão de relacionar teoria e prática, durante a vida acadêmica do aluno, por meio do estágio supervisionado, destaca-se o embasamento legal. De acordo com o Decreto $\mathrm{n}^{\mathrm{o}}$ 87.497, de 18 de agosto de 1982, regulamentado pela Lei $\mathrm{n}^{\circ}$ 6.494, de 07 de dezembro de 1977, este dispõe sobre o estágio de estudantes de estabelecimentos de ensino superior, de ensino médio regular (antigo $2^{\circ}$ grau) e supletivo, no art. $2^{\circ}$, a saber:

Considera-se estágio curricular [...] as atividades de aprendizagem social, profissional e cultural, proporcionadas ao estudante pela participação em situações reais de vida e trabalho de seu meio, sendo realizadas na comunidade em geral ou junto a pessoas jurídicas de direito público ou privado, sob responsabilidade e coordenação da instituição de ensino. (BRASIL, 1982, s.p.)

Sendo assim, também é importante mencionar que professor e aluno precisam aprender a conviver com as diferenças, entre tanto, os processos educativos tem que ocorrer como um fenômeno social e cultural, onde a reflexão sobre o saber e suas relações é continuamente redimensionada em 
uma "negociação" e "recriação" dos significados. Tendo o diálogo entre professor e aluno como elemento norteador para a construção do conhecimento em uma dimensão reflexiva. Desta forma, o estágio curricular supervisionado permitirá que o aluno de licenciatura observe a realidade da sala de aula e as situações que deverá enfrentar com maior ou menor dificuldade (SCALABRIN; MOLINARI, 2013).

Reitera-se que o estágio supervisionado deve acontecer durante a vida acadêmica, tendo início com a observação, com atividades complementares, práticas pedagógicas, pois isso proporciona maior probabilidade de sucesso tanto no estágio curricular supervisionado como na formação profissional.

Portanto, o estágio curricular supervisionado é uma prática imprescindível, em razão de apresentar grandes benefícios para a aprendizagem e para o progresso do ensino em relação à sua formação. Em suma, é preciso levar em conta a importância de se colocar em prática uma atitude reflexiva logo no início da carreira de educador, pois isso será o fio condutor que levará o estudante a vivenciar na prática o que estudou na Universidade.

Em outros termos, é um instrumento que pode fazer a diferença para quem está iniciando no campo de trabalho ligado à educação e, dessa forma, tendo a oportunidade de transformar a lamentável realidade da educação em nosso país, nos dias de hoje, que se encontra longe de ser satisfatória. A fala de uma estagiária é elucidativa nesse caso:

O estágio supervisionado no ensino de Geografia propicia a compreensão de saberes e
auxilia na inter-relação de escola-universidade. Durante a realização do estágio, ficou cada
vez mais evidente essa necessidade da aproximação da teoria e prática. A dificuldade que
encontramos dentro de sala decorrente dos alunos serem diferentes, por complexidade de
diferentes niveis de aprendizagem, faz-se necessário que o professor saiba lidar com essas
dificuldades procurando solucionar da melhor forma para todos. Nessa solução de
dificuldades, é onde acontece a formação da identidade profissional, pois será o momento
de adequarmos os conteúdos para atender essas diferenças. A universidade nos oferece
conhecimento científico, mas a metodologia pedagógica somos nós que construímos no
decorrer do tempo e de acordo com cada turma. Diante disso, se vêa importância do estágio
e deve-se ter comprometimento, responsabilidade e respeito no compromisso que está
assumindo como futuro educador. (P. K. O.).

Nesse viés, durante sua permanência na escola em que realizará o estágio curricular supervisionado, o acadêmico irá constatar como é o espaço escolar, a sala de aula, como ocorre o método de intercâmbio entre educador e educando. Essas observações sensatas oportunizam aos futuros professores informações de como se dá o processo de ensino e aprendizagem no ensino fundamental e médio da educação básica. O que se percebe no comentário do estagiário que diz o seguinte: 
Durante o percurso de formação, em incontáveis momentos, a turma foi orientada pelos professores sobre os desafios da sala de aula no estágio, no entanto, nada do que ouvi e li me preparou para a dimensão dos desafios da prática, o contato com alunos adolescentes de classes e comportamentos sociais variados, além da adaptação a planejamentos de conteúdos e domínio dos mesmos. Porém, percebo que saio do estágio como uma pessoa melhor, com respeito às limitações e às diferenças. Além disso, passo a pensar no estágio como um espaço de aprendizado com o maior potencial de todo o curso de formação, saio do exercício da experiência prática sensibilizado pelas dificuldades de aprendizado de alguns alunos, mas saio com sentimento de que me dediquei e imprimi esforço para oferecer o meu melhor àqueles alunos e à instituição. (N. G.).

Portanto, a realização do estágio supervisionado estabelece um experimento marcante, fato que contribuirá para a realização de um trabalho cada vez mais consciente, evitando situações extremas na realização de qualquer atividade em sala de aula, facilitando, deste modo, o método de aprendizagem dos estudantes.

Não obstante a isso, o estágio curricular supervisionado é incontestável, pois é um dos momentos mais significativos de qualquer curso de graduação. Os estudantes criam perspectivas em relação ao que vai ocorrer nesse tempo, uma vez que, após a ênfase nos conhecimentos teóricos, é o momento de colocar em prática tudo aquilo que foi discutido durante o curso de formação, levando, assim, a teoria à prática em sala de aula. Cinelli et al., (2019) destacam a importância de todo o processo de formação acadêmica, ou seja, o embasamento teórico visto em sala de aula é de grande valia para a realização do estágio curricular supervisionado, pois é o conhecimento científico que o estagiário colocará em prática.

De acordo com Tardif (2002), devem ser destacados também os problemas ou as dificuldades encontradas na prática do estágio supervisionado em virtude de ser uma situação nova. Até mesmo pelo fato de que as instituições de ensino não estavam habituadas a receber estudantes, pois se verificou que as escolas não estão organizadas de forma satisfatória, ou não têm muito empenho para coordenar estudantes. Embora isso tenha se modificado, ainda percebe-se este fato nos dias de hoje, como pode ser observado nas seguintes falas:

Diante da experiência vivenciada, do estágio na escola [...], que contribuiu de forma significava para conhecermos de perto o futuro ambiente de trabalho, e as dificuldades a serem enfrentadas, nota-se a necessidade dos cursos de licenciatura e as escolas trabalharem e buscarem alternativas inovadoras, para contribuição no desenvolvimento dos educandos, que são o futuro da sociedade. O estágio serviu de aprendizado para que busquemos novas ideias e práticas capazes de enfrentar os problemas apresentados nas salas de aula e no ambiente escolar, fazendo com que os alunos continuem acreditando que a educação é a melhor forma de introduzi-los na sociedade. (M. C. T. S.).

Foi discutida a importância do estágio para a formação dos graduandos em licenciatura, pois é a etapa inicial para a maioria dentro do ambiente escolar, proporcionando a oportunidade de adquirir novas experiências [...]. Podemos perceber que o Estágio 
Supervisionado é uma ferramenta de extrema importância para a formação dos professores, pois possibilita uma reflexão sobre a teoria e a prática, e sobre as práticas metodológicas, qual é melhor para cada tipo de aluno, para cada tipo de sala, levando em consideração as especificidades de cada um. (M. A. R. B.).

Conforme os relatos acima elencados percebe-se que depois do estágio curriculares supervisionado realizado, no decorrer da atuação docente, os saberes concebidos durante as experiências proporcionaram aos estagiários a oportunidade de ministrarem seus conhecimentos de uma forma que facilite a aprendizagem dos estudantes, de modo claro e preciso, sendo cada vez mais objetivo e prático em sua função.

Nesse contexto, Tardif (2002) acrescenta que a profisssão de um professor pode ser construída com base em quatro pilares: os saberes da formação profissional; os saberes disciplinares; os saberes curriculares e os saberes experienciais, que são edificados no decorrer de seu cotidiano e podem ser observados na fala da estagiária:

\begin{abstract}
A realização do estágio, além de ser uma obrigatoriedade como pré-requisito para se encerrar um curso, carrega consigo uma bagagem de experiência e demonstração da realidade a ser vivida como rotina para aqueles que pretendem seguir a carreira. Sendo assim, a observação e o estágio foram importantes, pois isso abriu a visão e nos deu a oportunidade de experimentar a sensação de estar em uma sala de aula, dirigindo conteúdos em busca dos conhecimentos dos alunos. Considero, assim, que o estágio supervisionado na Modalidade do EJA foi significante, pois, embora seja para alunos de diferentes idades, todos constituem os mesmos objetivos de aprender e encerrar uma etapa de sua vida em relação ao sistema educacional. No entanto, as responsabilidades que temos em nossas mãos são de certa forma surpreendentes, pois eles confiam em nossa capacidade de conseguir adequar diversos conceitos para sua realidade e condição social. Conclui-se que os momentos vividos de observação e regência no campo serviram para refletir e analisar nossa formação e aprendizado. Conhecer o ambiente escolar e estar inserido nele por tempo determinado nos traz a compreensão de que nossa graduação irá nos permitir voltar naqueles espaços, novamente, para trabalhar cotidianamente com a diversidade cultural que os alunos trazem dentro de si e contribuir assim para uma educação futura. (V.S. P.).
\end{abstract}

Guebert (2008) afirma que é de suma importância destacar que todo processo de construção precisa de uma referência. Neste caso, o professor se apresenta como o responsável por ser esta, e diante disso sua postura e ações devem demonstrar seu desejo de auxiliar os alunos nesse processo. Assim, as questões que tem influência sobre o desenvolvimento da cognição e da linguística dos alunos, bem como as interações entre esses processos, vão influenciar também o estilo de comunicação do professor.

Nesse sentido, o relato do estagiário é elucidativo:

Dá-se muita importância à prática do professor, entretanto, para isso, o coletivo da escola muito contribui, pois, se há parceria entre os profissionais, o sucesso é garantido, tendo em vista que a interação entre as pessoas proporciona um melhor fazer pedagógico, considerando que normalmente 
parte sempre de discussões em grupo e, neste caso, possíveis erros são corrigidos antecipadamente. Corroborando com a discussão, a estagiária traz a seguinte colocação:

\begin{abstract}
Durante o estágio, na formação do graduando em licenciatura, pois no estágio ele se depara com uma realidade que não é contada em sala de aula durante a sua formação, então é nesse momento que ele decide se continua ou não, porque sabemos que para ser professor temos que ter consciência do tamanho da responsabilidade que temos em nossas mãos, temos que querer estar ali, e não estar somente por obrigação. A escola nos proporcionou uma experiência única e fundamental para nossa futura carreira profissional, adquirimos práticas importantes, passamos a ter noção da real importância do papel do professor na educação básica, onde o professor regente permitiu que tivéssemos liberdade durantes as aulas, assim tivemos a oportunidade de colocar nossa ideia em ação, levamos para esses alunos algo diferente e diversificado, e o resultado foi satisfatório porque todos participaram. (J. R. L. C.).
\end{abstract}

Acrescenta-se, ainda, sobre a possibilidade de cursar o ensino superior (no caso, a Geografia) como oportunidade de autonomia cidadã, por isso, muitos alunos chegam à conclusão, a partir do estágio, de que a docência não é o objetivo deles, e sim a oportunidade de alcançar melhores empregos e remunerações por possuírem um curso superior.

[...] para concluir o curso de nível superior, houve a necessidade de se cumprir a fase de monitoria e regência no Ensino Médio. A monitoria foi a etapa de conhecimento do ambiente, bem como os alunos, auxiliando o professor nas aulas e os alunos no que precisavam, e durante a regência, a fase em que de fato incorpora a posição de docente e a responsabilidade de ensinar. Embora a escola seja referência em estrutura e suporte ao ensino, uma das grandes fragilidades enxergadas foi a questão cultural familiar para o ensino-aprendizagem, ao presenciar a negligência que os pais apresentam não só pela instituição, mas também com os próprios filhos, estes que muitas vezes deixam de estudar para fazer uso do celular, formando alunos deficientes em leituras, semianalfabetos, entre outros. Tal comportamento que estes possuem é reflexo do que é visto e vivido em casa, o que torna um desafio para a docência e para a missão de mediar o conhecimento. (V. C. F. S.).

De acordo com Carvalho et al. (2003), no projeto pedagógico de um curso de licenciatura, a prática como componente curricular e os estágios supervisionados devem ser vistos como momentos singulares de formação para o exercício de um futuro professor, o estágio ainda com maior ênfase, pois é no estágio que o acadêmico terá um momento único para ampliar sua compreensão da realidade educacional e do ensino, tendo uma relação direta com os alunos e com a escola, como declara a estagiária:

\footnotetext{
Para motivar os professores, a escola, todas as segundas-feiras, realiza o momento com Deus, em que é lido um trecho da Bíblia e é feita uma oração para que comecem a semana bem e de bom ânimo para continuar a transformar pessoas e lugares.Manter um bom feedback com os professores do quadro de funcionários é uma ótima forma de absorção de experiência docente, pois por terem mais tempo com os alunos, conhecem qual estratégia seria mais adequada para determinado ano, sala e aluno. Uma forma de obter conhecimento da prática do ensino-aprendizagem é a partir de exemplos da vida real e assim enriquecer os recursos didáticos requeridos. (V. C. F. S.).
} 
Nesse sentido, constatamos que os estagiários concebem a profissão do professor como uma profissão do conhecimento (MARCELO, 2009; IMBERNÓN, 2011). Assim, ficou evidente que a formação do profissional do conhecimento acontece por meio da atualização dos conteúdos disciplinares que leciona. No entanto, para os estudiosos da formação de professores, formar docentes não é apenas atualizar os conhecimentos da disciplina e transmiti-los aos alunos. Observamos isso na seguinte explicação do estagiário V. C. F. S.: "O conhecimento é fundamental para o docente. Somente com o domínio do conteúdo é possível desenvolver um bom trabalho em sala de aula [...].”

Para os estudantes estagiários pesquisados, a vocação para a docência foi justificada como uma das melhores definições, por que:

O professor está em constante construção do conhecimento. Ele não pode parar. Precisa se atualizar e ser um eterno buscador de novos conhecimentos que complementam o que já se sabe. Observei isso na escola pela formação continuada e as perguntas sempre pertinentes por parte de alguns alunos em sala na hora da minha prática em sala do estágio. (M. A. R. B.).

Destaca-se que a relação universidade/escola permite que futuros professores aprendam a compreender a escola como um organismo em desenvolvimento, caracterizado por uma determinada cultura, clima organizacional, dotada de algumas funções de gestão necessárias para garantir seu funcionamento.

\section{CONSIDERAÇÕES FINAIS}

Ser um profissional do ensino fundamental e médio, na sociedade contemporânea, não é tarefa fácil, visto que existem diversos fatores capazes de influenciar o exercício profissional docente, desde sua formação até a constituição profissional. Com base nesta assertiva, o presente artigo objetivou justificar a relevância do estágio para o curso de licenciatura em Geografia, da Universidade do Estado de Mato Grosso.

$\mathrm{O}$ artigo revela algumas discussões, realizadas em sala de aula, pelos estudantes do oitavo semestre. Assim, tal etapa teve como finalidade a prática no ensino médio e baseou-se em concepções dos estagiários pesquisados sobre a profissão docente. O intuito foi colaborar para o objetivo geral deste estudo, que é justificar a importância do estágio para curso mencionado, em razão de promover maior integração entre a aprendizagem acadêmica e a compreensão da dinâmica das instituições de ensino da educação básica. 
Além disso, reforça a importância do conceito de participação na prática do estágio para o futuro licenciado, além de abordar os resultados originados apenas com o caderno de campo e com os artigos de trabalho final dos estudantes. Nesse viés, esse desafio sugere a necessidade de um processo contínuo de formação de professores. Para tanto, faz-se necessário conceber o estágio supervisionado como um projeto político-pedagógico, sobre o qual o aluno se debruçará na intenção de aprimorar sua compreensão geográfica e desenvolver o pensamento crítico para explicar o mundo e suas transformações.

É relevante mencionar que os estudantes de licenciatura pesquisados utilizaram com frequência a palavra dedicação. De fato, todo o processo de formação e a realização do estágio assim exigem. Também, falou-se diversas vezes em vocação, pois a profissão docente requer aptidão para essa empreitada. No geral, na concepção desses estudantes, após o compromisso, ou com ele, a docência demanda dedicação, enfim.

Ainda nesse sentido, os estagiários demonstraram a compreensão de que existe um compromisso político-social na docência, que implica na consideração de que ser professor transcende ensinar conteúdos socialmente partilhados e estabelecidos, que é a intencionalidade da profissão, mas, por trás do exercício profissional docente, há a formação de sujeitos cidadãos que têm capacidade crítica e buscam a transformação nos diversos níveis.

Em suma, valendo-me dos aspectos observados, insiste-se na ideia de que este artigo, longe de fornecer soluções prontas e acabadas, é um convite à reflexão acerca da formação de professores licenciados em Geografia.

\section{REFERÊNCIAS}

ALMEIDA, E. D; MELLO, S. N. Supervisão pedagógica na gestão escolar: trabalhando direitos humanos e cidadania a partir da literatura infantil. Rev. Educ. Púb., v. 19, n. 8, abr. 2019. Disponível em:

$<$ https://educacaopublica.cecierj.edu.br/artigos/19/8/supervisão-pedagogica-na-gestao-escolartrabalhando-direitos-humanos-e-cidadania-a-partir-da-literatura-infantil>. Acesso em: 20 jan. 2020.

CALLAI, H. C. Educação geográfica: reflexão e prática. 2. ed. Ijuí: UNIJUÍ, 2010.

CARVALHO, L. M. C.; DIAS-DA-SILVA, M. H. G. F.; PENTEADO, M.; TANURI, L. M.; LEITE, Y. F.; NARDI, R. Pensando a licenciatura na UNESP. Rev. Nuances, Presidente Prudente, a. 9, n. 9/10, p. 211-232, 2003. 2 Disponível $<$ https://revista.fct.unesp.br/index.php/Nuances/article/view/405/440>. Acesso em: 23 jan. 2020. 
CINELLI, A. P. M. OLIVEIRA, R. C. de.; OLIVEIRA, S. M. de.; SILVA, J. M. da.; KNAUT, M. S. J. A importância da formação continuada para o desenvolvimento pedagógico. Rev. Práxis, n. 9, p. 1-7, 2019. Disponível em: <www.opet.com.br/faculdade/revista-praxis/pdf/n9/GESTAO-AIMPORTANCIA>. Acesso em: 23 jan. 2020.

FÁVERO, M. L. A. Universidade e estágio curricular: subsídios para discussão. In: ALVES, N. (org.) Formação de professores: pensar e fazer. São Paulo: Cortez, 1992. p. 53-71.

FERNANDES, J. L.; NASCIMENTO, L. S. O estágio como campo de pesquisa e a sua contribuição para a construção da identidade profissional docente. 1. ed. Campina Grande, Realize, 2012.

FONSECA, J. J. S. Metodologia da pesquisa científica. Fortaleza: UEC, 2002. Apostila.

FREIRE, P. Pedagogia da autonomia: saberes necessários à prática educativa. 3. ed. São Paulo: Paz e Terra, 2007.

HAGUETE, T. M. F. Metodologias Qualitativas na Sociologia. 3. ed. Petrópolis: Vozes, 1987. IMBERNÓN, F. Formação docente e profissional - formar-se para a mudança e a incerteza. 1. ed. São Paulo: Cortez, 2001.

LIMA, M. S. L. A formação contínua dos professores nos caminhos e descaminhos do desenvolvimento profissional. 2001. Tese (Doutorado em Educação) - Faculdade de Educação da Universidade de São Paulo, São Paulo.

MARAFON, G. J.; ARAÚJO, J. S. Borborema; TEÓFILO, V. M. S. A formação do professor pesquisador nos cursos de licenciatura da uerj/cederj: o lugar e a importância da pesquisa no curso de formação em licenciatura em geografia da uerj/cederj no sistema semipresencial. Geo UERJ, n. 36, p. 48437, 2020.

MARCELO, C. Desenvolvimento profissional docente: passado e futuro. Ciências da Educação, n. 8, p. 7-22, 2009. Disponível em: $<$ http://www.unitau.br/files/arquivos/category_1/MARCELO_Desenvolvimento_Profissional_Do cente_passado_e_futuro_1386180263.pdf $>$. Acesso em: 25 jan. 2020.

PIMENTA, S. G. O estágio na formação de professores: unidade, teoria e prática? 3. ed. São Paulo: Cortez, 1997.

PIMENTA, S. G.; LIMA, M. S. L. Estágio e docência. 1. ed. São Paulo: Cortez, 2008.

PONTUSCHKA, N. N.; PAGANELLI, T. I.; CACETE, N. H. Para ensinar e aprender Geografia. 3. ed. São Paulo: Cortez, 2001.

RODRIGUES, M. A. Quatro diferentes visões sobre o estágio supervisionado. Rev. Bras. Educ., Rio de Janeiro, v. 18, n. 55, p. 1009-1034, 2013. Disponível em: $<$ https://www.scielo.br/scielo.php?pid=S1413-24782013000400011\&script=sci_abstract\&tlng=pt $>$. Acesso em: 30 jan. 2020. 
SANTOS, M. Por uma outra globalização: do pensamento único à consciência universal. 16. ed. Rio de Janeiro: Record, 2008.

SCALABRIN, I. C.; MOLINARI, A. M. C. A importância da prática do estágio supervisionado nas licenciaturas. Rev. Unar, v. 7, n. 1, p. 1-12, 2013. Disponível em: $<$ http://revistaunar.com.br/cientifica/documentos/vol7_n1_2013/3_a_importancia_da_pratica_estagi o.pdf>. Acesso em: 25 jan. 2020.

STRAFORINI, R. A totalidade do mundo nas primeiras séries do ensino fundamental: um desafio a ser enfrentado. Rev. Terra Livre, São Paulo, v. 1, n. 18, p. 95- 114, 2002. Disponível em: 